\title{
CLINICAL PRACTICE Clinical Vignettes Unexplained Symptomatic Paroxysmal Hypertension: a Diagnostic and Management Challenge
}

\author{
Kelly Dyer, $M D^{7}$ and Theresa E. Vettese, $M D^{2}$
}

'Emory University School of Medicine, Atlanta, GA, USA; ${ }^{2}$ Division of General Medicine and Geriatrics, Department of Medicine, Emory University School of Medicine, Atlanta, USA.

J Gen Intern Med 35(2):586-9

DOI: $10.1007 / \mathrm{s} 11606-019-05503-8$

(c) Society of General Internal Medicine 2019

\section{INTRODUCTION}

Symptomatic paroxysmal hypertension is considered the hallmark symptom of pheochromocytomas. Pheochromocytomas, however, are exceedingly rare and are diagnosed in $2 \%$ of patients with hypertensive paroxysms. ${ }^{1}$ As a result, clinicians and patients are often left frustrated and confused when a diagnostic evaluation of symptomatic paroxysmal hypertension is un-revealing for a pheochromocytoma. Frequently, these patients undergo multiple and often unnecessary testing, as was the case with our patient. The differential diagnosis is broader than most clinicians realize and includes conditions such as prescription and illicit drug use, obstructive sleep apnea, panic attacks, and pseudopheochromocytoma. Of these, pseudopheochromocytoma is perhaps the least understood and considered.

\section{CASE}

A 58-year-old woman with a past medical history of well controlled HIV and a diagnosis of seizure disorder presented with severe hypertension and headache. According to the patient's husband, she was in her usual state of health until that morning when she developed abrupt onset of severe headache, nausea, palpitations, and anxiety. He reported that the patient had experienced previous similar episodes and had received care in multiple other hospitals. He also noted that the patient's episodes were always preceded by an emotional stressor.

On physical examination in the emergency department, the patient was noted to be drowsy. While alert and oriented with normal speech, she was reluctant to answer questions, stating that she was "too tired." Her blood pressure at presentation

Prior presentations The manuscript was previously presented at the American College of Physicians Georgia Chapter Conference in Atlanta, in 2018.

Received November 14, 2018

Revised May 31, 2019

Accepted October 10, 2019

Published online November 8, 2019 was $260 / 120 \mathrm{mmHg}$ with a heart rate of 130 beats per minute and normal respiratory rate and oxygen saturation. The patient's blood pressure quickly dropped to $98 / 62 \mathrm{mmHg}$ after receiving intravenous (IV) labetalol. Abdominal exam revealed generalized tenderness to palpation with mild voluntary guarding. The remainder of the physical examination was normal. Initial laboratory tests were revealing for an elevated white blood cell count of 18,000 cells per microliter but otherwise normal complete blood count, comprehensive metabolic profile, serum cardiac biomarkers, and urine drug screen. Magnetic resonance imaging/magnetic resonance angiogram of the brain (MRI/MRA) and 24-h electroencephalogram (EEG) were unremarkable. The patient was admitted to the hospital with a diagnosis of hypertensive urgency. She did not require any additional antihypertensive medications as she became hypotensive with the initial dose of labetalol and remained normotensive thereafter. An evaluation for the etiology of severe paroxysmal hypertension, such as pheochromocytoma, was initiated.

Over the next $24 \mathrm{~h}$, the patient's fatigue resolved and she was able to participate in giving additional history. The patient stated that she had been experiencing recurrent episodes of headache, nausea, diaphoresis, and shaking followed by extreme fatigue for the past year. The episodes were associated with extremely elevated and labile blood pressures. The patient was hospitalized three times for these spells over the past 3 months. While the patient's husband reported a temporal relationship to emotional stress, the patient herself denied it. Her previous evaluation was extensive and included a secondary hypertension work up which was unremarkable. Additionally, she had brain MRI/MRA, 24-h EEG monitoring, and a lumbar puncture with infectious work up with each hospitalization, all of which were negative. These prior episodes had been diagnosed as hypertensive encephalopathy and secondary seizures due to her presenting severe hypertension, her partner's description of "shaking," and prolonged fatigue following each episode. Given the increasing frequency of her events, antiepileptic drugs (AEDs) were initiated and doses progressively increased during each hospitalization until she was taking three drugs at maximum doses.

Just prior to planned discharge, the patient experienced a witnessed event which her husband reported was consistent with her prior spells. The patient developed abrupt severe hypertension and tachycardia with headache, nausea, and 
diaphoresis. During the episode, she was noted to have tremors of her upper extremities but no loss of consciousness or tonic-clonic activity. Plasma fractionated metanephrines were redrawn during the episode. The patient again responded to intravenous labetalol. The following day she reported a stressful phone call with family members prior to her event, although she did not attribute being emotional as the precipitant. The patient experienced no further episodes over the next $48 \mathrm{~h}$ and was ultimately discharged on carvedilol and short acting anxiolytics as needed. Given that the patient's witnessed episode was not consistent with a seizure, her antiepileptic drugs were gradually discontinued.

The patient's plasma fractionated metanephrines returned following discharge. Results from serum taken during the witnessed episode revealed plasma metanephrines two to three times the reference range $(157 \mathrm{pg} / \mathrm{ml}$, normal $<57 \mathrm{pg} / \mathrm{mL})$ and plasma normetanephrine elevated to four times the reference range $(664 \mathrm{pg} / \mathrm{mL}$, normal $<148 \mathrm{pg} / \mathrm{mL})$ concerning for pheochromocytoma. The patient underwent computerized tomography $(\mathrm{CT})$ of the abdomen and pelvis with contrast as an outpatient for further work up which demonstrated normal adrenal glands and no evidence paraganglioma. Repeat plasma metanephrines were also performed and were within normal limits corroborating a false positive elevation during her episode. Thus, based on her negative evaluation, a presumptive diagnosis of pseudopheochromocytoma was made. The patient has had no further admissions to the hospital 5 months later.

\section{DISCUSSION}

Pseudopheochromocytoma was first described by Kuchel in 1981. ${ }^{2}$ Subsequently, the syndrome has been described in several case studies and series. Pseudopheochromocytoma is a clinical constellation characterized by the sudden onset of hypertensive paroxysms with peak blood pressures of $>200 / \geq$ 110 during episodes. ${ }^{3-5}$ Physical symptoms of headache, diaphoresis, nausea, fatigue, and dizziness ${ }^{3,4}$ may also accompany each event. Evaluation for pheochromocytoma in these patients is negative. In most cases, a history of severe abuse, trauma, or a defensive personality style ${ }^{5,6}$, characterized by a lifelong pattern of coping with distressful emotions with repression and dissociation, is also present. Events last anywhere from 10 min to 2 days $^{4}$ and occur with a frequency ranging from several times a day to less than once a month ${ }^{3}, 4$. Episodes tend to be followed by intense fatigue that can last several days ${ }^{7}$ and are often debilitating for patients.

The pathophysiology of pseudopheochromocytoma remains poorly understood but dysregulation of the sympathetic nervous system has been implicated in several studies. ${ }^{3,8,9}$ In one study, glucagon was used to stimulate the sympathetic nervous system in patients with normotension, essential hypertension, and pseudopheochromocytoma. Elevations in both epinephrine and norepinephrine were greater in pseudopheochromocytoma suggesting possible adrenoreceptor hypersensitivity in these patients. ${ }^{3}$ Another study found that patients with pseudopheochromocytoma had a marked and prolonged elevation in systolic blood pressure in response to the Valsalva maneuver relative to patients with pheochromocytoma. It was postulated that the high blood pressure reactivity to Valsalva in pseudopheochromocytoma was due to hyperactivity in both the alpha and beta-adrenergic receptor functions while low blood pressure reactivity in pheochromocytoma was due to desensitization of adrenergic systems by chronic catecholamine excess. ${ }^{8}$ These studies highlight the pathophysiologic differences between pseudopheochromocytoma and the disorders that mimic it.

Clinically, however, pseudopheochromocytoma may be much harder to differentiate from other similar presenting conditions including pheochromocytoma and panic attacks and the clinician should remain astute for other clinical clues. For example, flushing is a symptom more often seen in pseudopheochromocytoma and panic attacks, as opposed to pheochromocytoma, where facial pallor is more common. ${ }^{10}$ Nausea is a distinguishing characteristic of pseudopheochromocytoma. While it is rare that patients with pseudopheochromocytoma experience an intense feeling of doom or fear, if they do it is in response to symptoms rather than preceding symptoms as in panic attacks. ${ }^{11}$ Table 1 contrasts the pathophysiology, clinical symptoms, exam and laboratory findings, and treatment of the different etiologies of symptomatic paroxysmal hypertension.

Although case series have demonstrated $67 \%$ of patients with pseudopheochromocytoma have a history of emotional trauma, ${ }^{4}, 5$ these patients usually refute the idea that their disorder may have a psychological origin, as was the case with our patient. ${ }^{5,11}$

Ultimately, however, pseudopheochromocytoma is considered a diagnosis of exclusion as the diagnosis of pheochromocytoma must be excluded. A greater than twofold elevation above the upper limit of normal in urine chatecholamines or elevated urine metanephrines or a greater than fourfold increase in fractionated plasma metanephrines is considered concerning for pheochromocytoma ${ }^{12}$ and warrants anatomical and functional abdominal imaging with either magnetic resonance imaging (MRI) or computerized tomography (CT). Negative results should prompt reassessment for an alternative diagnosis given the high sensitivity of these imaging modalities for detecting a pheochromocytoma, as in our patient's case. ${ }^{13}$

Reflecting the link with the sympathetic nervous system, some patients with pseudopheochromocytoma may have equivocal catecholamine levels during paroxysms (between the upper reference limit and four times the upper reference limit) that may call for further testing to exclude pheochromocytoma, but mild elevations are common ${ }^{6}$ and often act as a red-herring that leads to an extensive search for a pheochromocytoma. In several studies examining this condition, patients with only mild elevations in catecholamines and negative imaging were subjected to surgical exploration for a pheochromocytoma despite evidence against its existence. ${ }^{3}$ Maintaining awareness of the diagnostic criteria for pheochromocytoma and remembering pseudopheochromocytoma as a 
Table 1 Differential Diagnosis of Symptomatic Paroxysmal Hypertension

\begin{tabular}{|c|c|c|c|c|c|}
\hline Diagnosis & Pathophysiology & $\begin{array}{l}\text { Clinical } \\
\text { presentation }\end{array}$ & Physical exam & Laboratory data & Treatment \\
\hline Pheochromocytoma & $\begin{array}{l}\text { Excess catecholamine } \\
\text { secretion from } \\
\text { catecholamine-secreting } \\
\text { tumors }\end{array}$ & $\begin{array}{l}\text { - Episodic headache } \\
\text { - Sweating } \\
\text { - Palpitations }\end{array}$ & $\begin{array}{l}\text { - Sustained or } \\
\text { paroxysmal } \\
\text { hypertension } \\
\text { - Tachycardia }\end{array}$ & $\begin{array}{l}\text { - Twofold or greater } \\
\text { elevation above upper limit } \\
\text { of normal in urine } \\
\text { catecholamines OR } \\
\text { elevated urine } \\
\text { metanephrines OR greater } \\
\text { than fourfold elevation of } \\
\text { plasma metanephrines }\end{array}$ & $\begin{array}{l}\text { - Pre- } \\
\text { operative al- } \\
\text { pha and beta } \\
\text { blockade } \\
\text { - Surgical } \\
\text { resection }\end{array}$ \\
\hline Pseudopheochromocytoma & $\begin{array}{l}\text { Unclear, likely activation } \\
\text { of sympathetic nervous } \\
\text { system due to emotional } \\
\text { factor; patients often fail to } \\
\text { report any triggering } \\
\text { emotional distress }\end{array}$ & $\begin{array}{l}\text { - Episodic headache } \\
\text { - Chest discomfort } \\
\text { - Dizziness } \\
\text { - Nausea } \\
\text { - Palpitations } \\
\text { - Flushing } \\
\text { - Sweating }\end{array}$ & $\begin{array}{l}\text { - Paroxysmal } \\
\text { hypertension }\end{array}$ & $\begin{array}{l}\text { - Normal or mild-moderate } \\
\text { elevation of levels of urine } \\
\text { cathecholamines, } \\
\text { metanephrines and/or plas- } \\
\text { ma metanephrines }\end{array}$ & $\begin{array}{l}\text { - Alpha-beta } \\
\text { blockade if } \\
\text { tolerated } \\
\text { - SSRI } \\
\text { - Cognitive } \\
\text { behavioral } \\
\text { therapy }\end{array}$ \\
\hline Panic disorder & $\begin{array}{l}\text { Neurobiologic and } \\
\text { psychosocial factors }\end{array}$ & $\begin{array}{l}\text { - Intense fear } \\
\text { proceeding other } \\
\text { symptoms AND 4/13 } \\
\text { of the following: } \\
\text { - Palpitations } \\
\text { - Sweating } \\
\text { - Trembling } \\
\text { - Dyspnea } \\
\text { - Feelings of choking } \\
\text { - Chest discomfort } \\
\text { - Nausea or } \\
\text { abdominal distress } \\
\text { - Feeling dizzy or } \\
\text { lightheaded } \\
\text { - Chills or heat } \\
\text { sensation } \\
\text { - Paresthesias } \\
\text { - Derealization or } \\
\text { depersonalization } \\
\text { - Feeling of losing } \\
\text { control or "going } \\
\text { crazy" } \\
\text { - Fear of dying }\end{array}$ & $\begin{array}{l}\text { - Mild } \\
\text { paroxysmal } \\
\text { elevations in } \\
\text { blood pressure } \\
\text { and heart rate }\end{array}$ & $\begin{array}{l}\text { - Normal levels of urine } \\
\text { cathecholamines, } \\
\text { metanephrines and normal } \\
\text { plasma metanephrines }\end{array}$ & $\begin{array}{l}- \text { SSRI } \\
\text { - Cognitive } \\
\text { behavioral } \\
\text { therapy }\end{array}$ \\
\hline
\end{tabular}

possible alternate diagnosis may prevent clinicians from doing harm in patients with symptomatic paroxysmal hypertension.

Differentiating between these conditions is paramount for treatment considerations. Treatment of pseudopheochromocytoma should be targeted towards pathophysiologic mechanisms. This is particularly relevant when considering an antihypertensive agent as both prophylaxis and an abortive measure for these patients. Treatment aimed at simultaneous alpha-beta blockade has been proven effective and is first line therapy. ${ }^{4,13,14}$ Dual agents such as carvedilol and labelatol are effective but less so than when alpha- and beta-blockade is achieved separately with individual medications such as atenolol and doxazosin. ${ }^{13}$ This is likely due to the unreliable bioavailability of lipophilic beta-blockers like carvedilol and labetalol as well as the increased control providers are afforded when titrating alpha and beta blockade separately. ${ }^{13,}{ }^{15}$ That said, lower or even normal blood pressure between episodes can limit prescribed doses of antihypertensive agents. $^{16}$

Additional options for treatment are aimed at the underlying psychological nature of the disease. Acute management of the paroxysms is possible with rapidly acting benzodiazepines. ${ }^{3}$ More recent data suggests that selective serotonin reuptake inhibitors (SSRI) are very effective in improving frequency of paroxysms in most patients. ${ }^{17}$

\section{CONCLUSIONS}

In summary, pseudopheochromocytoma is an underappreciated but common cause of symptomatic paroxysmal hypertension. There is limited research and awareness about the disease despite its prevalence and effective treatment. A pheochromocytoma, which is much less common, is far more often considered as a diagnosis. As a result, patients with pseudopheochromocytoma are often subjected to repeated evaluation and unnecessary treatments despite compelling evidence that they have an alternative diagnosis. We believe that this case highlights the importance of considering pseudopheochromocytoma as a possible diagnosis in patients with symptomatic paroxysmal hypertension in order to facilitate appropriate treatment and avoid unnecessary testing and procedures.

Contributors: There were no further contributors to the paper. Contributors all met criteria for authorship. 
Corresponding Author: Kelly Dyer, MD; Emory University School of Medicine, Atlanta, GA, USA (e-mail: kedyer@emory.edu).

\section{Compliance with Ethical Standards:}

Conflict of Interest: The authors declare that they do not have a conflict of interest.

\section{REFERENCES}

1. Pacak K, Linehan WM, Eisenhofer G, Walther MM, Goldstein DS Recent advances in genetics, diagnosis, localization, and treatment of pheochromocytoma. Ann Intern Med. 2001;134 (4):315-329.

2. Kuchel O, Buu NT, Hamet P, Larochelle P, Bourque M, Genest J. Essential hypertension with low conjugated catecholamines imitates pheochromocytoma. Hypertension. 1981;3(3):347-355.

3. Sharabi Y, Goldstein DS, Bentho O, Saleem A, Pechnik S, Geraci MF, Holmes C, Pacak K, Eisenhofer G. Sympathoadrenal function in patients with paroxysmal hypertension: pseudopheochromocytoma. J Hypertens. 2007;25(11):2286-2295.

4. Mann SJ. Severe paroxysmal hypertension (pseudopheochromocytoma): Understanding the cause and treatment. Arch Intern Med. 1999;159 (7):670-674.

5. Mann SJ. Severe paroxysmal hypertension: An automatic syndrome and its relationship to repressed emotions. Psychosomatics. 1996;37(5):444450 .

6. Mann SJ. Severe paroxysmal hypertension (pseudopheochromocytoma). Curr Hypertens Rep. 2008;10 (1):12-18.

7. Mackenzie IS, Brown JB. Pseudopheochromoctyoma. J Hypertens. 2007;(24):2204-2206.

8. Hamada M, Shigematsu Y, Mukai M, Kazatani Y, Kokubu T, Hiwada K. Blood pressure response to the Valsalva maneuver in pheochromocytoma and pseudopheochromocytoma. Hypertension. 1995;25(2):266-271.

9. Kuchel O, Buu NT, Hamet P, Larochelle P, Bourque M, Genest J. Dopamine surges in hyperadrenergic essential hypertension. Hypertension. 1982;4(6):845-852

10. Pickering T, Clemow L. Paroxysmal hypertension: The role of stress and psychological factors. J Clin Hypertens. 2008; 10 (7): 575-581.

11. Eisenhofer G, Sharabi Y, Pacak K. Unexplained symptomatic paroxysmal hypertension in pseudopheochromocytoma: A stress response disorder? Ann N Y Acad Sci. 2008; 1148: 469-478.

12. Dobri G., Bravo E., Hamrachian A. Pheochromocytoma: Pitfalls in the biochemical evaluation. Expert Rev Endocrinol Metab. 2014; 9 (2): 123135.

13. Martucci VL, Pacak K. Pheochromocytoma and Paraganglioma: diagnosis, genetics, management and treatment, Curr Probl Cancer. 2014; 38(1): 7-41.

14. Mann SJ. Labile and Paroxysmal Hypertension: Common Clinical Dilemmas in Need of Treatment Studies. Curr Cardiol Rep. 2015; 17(11):99.

15. Mann SJ. Redefining beta-blocker use in hypertension: selecting the right beta-blocker and the right patient. J Am Soc Hypertens. 2017;11(1):54-65

16. Mann SJ. Neurogenic hypertension: Pathophysiology, diagnosis and management. Clin Auton Res. 2018; 28: 363-374.

17. Vaclavik J, Krenkova E, Vaclavik T, Kamasova M. Effect of sertraline in paroxysmal hypertension. Biomed Pap Med Fac Univ Palacky Olomouc Czech Repub. 2018; 162 (2): 116-120.

Publisher's Note Springer Nature remains neutral with regard to jurisdictional claims in published maps and institutional affiliations. 